\title{
REFLEX̃̃ES SOBRE O CONCEITO DE INTELIGÊNCIA
}

\author{
Henrique Figueiredo Machado de Oliveira \\ Departamento de Polícia Federal - Brasil

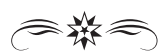

\begin{abstract}
RESUMO
Este artigo faz uma reflexão sobre o conceito de inteligência, por meio de uma revisão de literatura de autores que são referência na área, notadamente do pesquisador americano Sherman Kent. Ao demonstrar a inexistência de uma definição que aborde de forma satisfatória os diversos elementos que permeiam essa atividade, bem como a multiplicidade de significados do termo, o trabalho procura alertar para os malefícios provocados por esta lacuna conceitual.
\end{abstract}

Palavras-Chave: Inteligência. Conceito de Inteligência. Sherman Kent. Definição trina.

\section{Introdução ho Conceito}

Em linhas gerais, a inteligência é uma atividade correlata às Ciências Sociais que busca explicar, estimar e predizer eventos. Para tanto, dados e informações são coletados e analisados em um processo sistemático e contínuo cujo resultado é um produto informacional de elevado valor agregado.

Mesmo não se tratando de uma ciência propriamente dita, duas características citadas acima aproximam a inteligência das atividades desempenhadas no meio acadêmico. A primeira é que, assim como os diversos ramos da ciência, a inteligência procura aproximar-se da verdade dos fatos. Verdade essa que nem sempre se apresenta de forma clara e evidente aos olhos de um observador comum.

A segunda característica é subsidiária da primeira. A fim de sobrepujar esse grande desafio que é compreender a realidade, tanto os cientistas quanto os profissionais de inteligência lançam mão de métodos que são bastante similares. Ambos partem do estabelecimento de premissas, passam por uma fase de levantamento de hipóteses e, através de um processo cognitivo/racional, procuram testá-las e validá-las. 
Da mesma forma que cada ramo da ciência se incumbe da exploração de uma determinada área do saber, a inteligência também não se debruça sobre todo e qualquer evento, tratando somente daqueles que possam representar problemas e/ou ameaças aos interesses de seus clientes finais. Nesse sentido, Cepik, que acredita ser o Estado o único usuário da inteligência, afirma:

No mundo real, porém, as atividades dos serviços de inteligência são mais amplas do que a espionagem e também são mais restritas do que o provimento de informações em geral sobre quaisquer temas relevantes para a decisão governamental. (CEPIK, 2001, p. 30-31).

Como se pode perceber, a matéria-prima da inteligência são os dados e as informações. Sendo assim, é de fundamental importância que o leitor se familiarize com significados atribuídos a esses termos dentro do contexto da atividade, pois nem sempre são os mesmos daqueles empregados pelo senso comum. Portanto, antes de se prosseguir com a tarefa de definir o conceito de inteligência, será feita uma pequena digressão, com a finalidade de explicar a semântica dada a alguns termos.

Dados são as unidades fundamentais e indivisíveis do saber. A menor dimensão do que é conhecido. Assim, comparando a realidade com um grande e complexo quebra-cabeça, os dados seriam cada uma de suas peças. De acordo com a Doutrina Nacional de Inteligência de Segurança Pública (DNISP):

Dado é toda e qualquer representação de fato, situação, comunicação, noticia, documento, extrato de documento, fotografia, gravação, relato, denúncia etc., ainda não submetida, pelo profissional de ISP, à metodologia de Produção de Conbecimento. (BRASIL, 2007, p. 12).

Já a palavra "informação" é doutrinariamente empregada em um sentido amplo, significando tudo aquilo que se sabe, que é conhecido. Tendo essa definição como parâmetro, informação seria um conjunto maior de coisas no qual o saber produzido pela atividade de inteligência estaria inserido, conforme argumenta Lowenthal (apud GONÇALVES, 2009, p. 12). Em sentido mais restrito, os profissionais de inteligência entendem informação como sendo o saber proveniente da reunião de dados que podem ter sofrido determinado processamento, mas que ainda não foram submetidos ao processo de análise.

Informação também é o nome dado a um produto da inteligência, um tipo de relatório confeccionado pelos órgãos de inteligência. Considera-se, portanto, este significado como sendo o sentido material do termo. 
Já o termo "informações", por sua vez, nem sempre diz respeito ao plural da palavra informação. No jargão da atividade, principalmente em alguns países da América Latina, a palavra "informações" designa a própria atividade de inteligência, ou seja, "informações" usualmente é empregado como sinônimo de inteligência.

Por fim, "conhecimento" é outro termo que merece atenção especial do leitor. Chama-se de conhecimento o produto da agregação de valor analítico a dados e informações (plural de informação em seu sentido restrito). Assim, o termo "conhecimento" nada mais é do que resultado final da atividade de inteligência.

Findados os esclarecimentos terminológicos, voltemos para a conceituação geral de inteligência. A partir dos estudos realizados, Marcos Cepik apregoa duas dimensões para o termo:

Nesta concep̧̧ão ampla, inteligência é o mesmo que conhecimento, ou informação analisada. [...] uma definição mais restrita diz que inteligência é a coleta de informaçôes sem o consentimento, a cooperação ou mesmo o conbecimento por parte dos alvos da ação. (CEPIK, 2001, p. 2).

Joanisval Gonçalves, após confrontar diversas definições dadas por autores estrangeiros, sintetiza:

Nessa perspectiva anglo-saxônica, inteligência seria a informação processada e analisada com o objetivo de assessorar o processo decisório. (GONÇALVES, 2009, p. 13).

Até o presente momento, foi apresentada uma visão geral e vaga do que seria a atividade de inteligência, qual seja, a ideia de um método que, a partir de dados e informações, produz conhecimento. Não obstante, já nas citações apresentadas acima, estão contemplados aspectos que refinam um pouco mais o conceito; o objetivo de assessorar o processo decisório e a coleta de informaçôes de forma sigilosa.

Constata-se, portanto, que outras questões que são determinantes para delineação do conceito de inteligência ainda devem ser abordadas. Entretanto, o estabelecimento de quais são esses elementos está vinculado ao ponto de vista do pesquisador, uma vez que essa não é uma discussão teórica pacificada.

Nesse sentido, Feitoza argumenta: 
Reflexões sobre o Conceito de Inteligência

Uma definição de inteligência que contenha os elementos essenciais de seus conceitos ainda não foi estabelecida de maneira univoca e induvidosa.

Na verdade, não há consenso sobre quais são os elementos essenciais caracterizadores da inteligência - o segredo, os fins, o método, a maneira de se organizar? (FEITOZA, 2011, p. 1028).

Desse modo, se por um lado desenvolver uma definição própria seria por demais pretensão, por outro eleger uma dentro da literatura consultada que contemple todos os elementos considerados essenciais por este autor não seria possível.

Sendo assim, a discussão sobre o conceito de inteligência prosseguirá pela análise da clássica definição trina apresentada por Sherman Kent em seu livro Strategic Intelligence for American World Policy, importante referência bibliográfica, cuja primeira edição foi publicada em 1949, uma vez que, na visão do autor desta pesquisa, tal entendimento é um dos grandes responsáveis pela confusão conceitual que sempre se verificou no terreno da atividade de inteligência.

\section{Definição trina de Kent}

Sherman Kent foi professor de História da Universidade de Yale nos EUA e, no período da Segunda Guerra Mundial e da Guerra Fria, tornou-se um proeminente colaborador da CIA. Durante a sua carreira no serviço secreto, destacou-se por disseminar na comunidade de inteligência os rigores metodológicos da academia, bem como por sistematizar e publicar as técnicas até então empregadas por estes profissionais.

A importância de Kent para o estudo e desenvolvimento da atividade de inteligência não advém apenas do fato de sua obra ter sido pioneira, mas principalmente pela qualidade e profundidade com que temas pertinentes à área foram abordados. Por essa razão, seus ensinamentos ainda são bastante atuais e a análise de sua obra é sempre uma tarefa surpreendente e enriquecedora. Assim, a despeito das críticas que aqui serão feitas a alguns pontos de vista defendidos por ele, ressalta-se a admiração e o respeito que o autor deste trabalho tem pelo pesquisador americano. 
Inicialmente, é necessário alertar-se que Kent, em sua obra, não discute a atividade de inteligência de forma indiscriminada. Pelo contrário, já no primeiro parágrafo do livro, ele explicita o recorte adotado, deixando bem claro qual categoria da inteligência é o objeto de seu estudo:

Informação ${ }^{1}$ significa conbecimento. Se não pode ser ampliada a ponto de significar todo o conhecimento, pelo menos significa um espantoso volume e variedade de conhecimentos. Este livro tratará apenas de uma fração do total, todavia, possivelmente, da fração mais importante. Tratará da parte conhecida em informações como "informaçóes positivas de alto nível do exterior". (KENT, 1967, p. 17, grifo nosso).

Na sequência, ele explica a delineação feita ao atribuir sentido aos termos "positivas", "de alto nível" e "do exterior":

Note-se o que está sendo excluido. Primeiro, todos os conhecimentos sobre a nossa situação interna estão postos de lado. Informações positivas do exterior são realmente externas quanto à finalidade, objetivo e substância. Elas não se relacionam com o que acontece nos Estados Unidos ou em seus territórios e possessões. Segundo, todos os conbecimentos de natureza policial são excluidos. A palavra "positiva" foi introduzida na frase, para destacar que as informaçôes em questão não tratam da tão falada "contra-informação" e contra-espionagem [...]. A palavra "alto nivel" foi empregada para excluir o que é designado por informações "operacionais", informações táticas e informações das pequenas formações militares em ação, conhecidas como informações de combate. O que resta são os conhecimentos indispensáveis ao nosso bem-estar e segurança. (KENT, 1967, p. 17).

Dessa forma, apesar de grande parte das questões tratadas por Kent terem validade, quando se discute um conceito geral para o termo "inteligência”, há de se ter em mente que, de acordo com a terminologia mais empregada nos dias atuais, sua obra versa apenas sobre inteligência estratégica externa tanto de estado quanto de defesa.

Alguns estudiosos dirão que isso se deve ao fato de que, na época em que Kent realizou seus estudos, a atividade de inteligência resumia-se apenas ao que foi tratado por ele. E que o fato de o objeto de estudo do pioneiro americano nos parecer atualmente apenas uma pequena fatia do

1 Acredita-se que, ao originalmente dizer information, Kent estava tentando passar o sentido de informações, ou seja, inteligência. Provavelmente a tradução como "informação" tenha sido um lapso, uma vez que não existe plural da palavra information na língua inglesa. 
bolo se deve à vigorosa evolução sofrida pela atividade durante a segunda metade do século XX.

Tal argumento é facilmente rechaçado pela própria análise do texto de Kent. Ao dizer "Este livro tratará apenas de uma fração do total, todavia, possivelmente, da fração mais importante", fica claro que ele concebia a existência de outras especialidades da inteligência e que intencionalmente reduziu o universo de estudo, abordando apenas um ponto específico. Além disso, segundo a literatura especializada, o emprego dos métodos e técnicas da inteligência dentro da atividade policial já se fazia presente nos Estados Unidos desde o início do século XX.

Em Intelligence 2000: Revising the Basic Elements, Bob Morehouse, mesmo esclarecendo que a maciça disseminação do uso da inteligência no campo da segurança pública ${ }^{2}$ se deu durante a segunda metade do século XX, cita uma investigação levada a cabo pelo Departamento de Polícia de Nova Iorque entre 1905 e 1909, na qual a inteligência teria sido utilizada de forma decisiva para combater uma máfia chamada Black Hand que explorava imigrantes italianos:

Um dos primeiros, e entre os mais conhecidos, usos da inteligência pela segurança pública foi contra a Sociedade "Black Hand" (Dpto. de Polícia de Nova Iorque 2000a e 2000b). A inteligência criminal foi fundamental na resolução dos assassinatos "Black Hand" de imigrantes italianos em Nova Iorque no inicio dos anos 1900. [...] Nos anos 1920 e 1930, a inteligência criminal foi usada de forma limitada pelas agências americanas e canadenses de segurança pública. (PETERSON, MOREHOUSE, WRIGHT, 2002, p. 3, tradução livre).

O que Sherman Kent essencialmente fez foi sistematizar, teorizar e trazer para o contexto acadêmico as experiências empíricas vividas por ele enquanto colaborador da ainda jovem Agência Central de Informações (CIA), órgão do governo americano incumbido de realizar inteligência externa.

Portanto, é mais do que natural, justificável e até mesmo recomendável, que, ao se empregarem os ensinamentos de Kent para o estudo e análise da inteligência enquanto conceito universal, ou mesmo para um de seus subconjuntos, procedam-se adaptações, adequações e relativizações.

2 Adotou-se o conceito de segurança pública como a melhor tradução para o termo anglo-saxônico law enforcement. 
De acordo com a obra de Kent (1967), o termo "inteligência" apresenta três significados distintos. Para ele, o termo inteligência pode ser entendido como:

a) O produto resultante da atividade. Neste contexto, inteligência seria o mesmo que conhecimento, o resultado da aplicação de um método cognitivo, racional e analítico a dados e informações; os documentos ou qualquer outro output produzidos e entregues a quem de direito. Esse é o sentido empregado, por exemplo, quando um oficial militar solicita aos seus subordinados: "Produzam inteligência sobre a logística do inimigo";

b) A organização que executa a atividade. Inteligência também significaria as agências, órgãos, departamentos, serviços, enfim, toda e qualquer estrutura organizacional (ou conjunto delas) que aplica aos dados e informaçôes o referido método cognitivo, racional e analítico. Sob essa concepção, a mesma palavra "inteligência" claramente muda de sentido ao ser proferida pelo oficial militar: "Chequem o que a inteligência tem sobre a logística do inimigo";

c) O processo, ou seja, a própria atividade. Aqui o termo apresentaria uma acepção mais abrangente, englobando todas as etapas do método cognitivo, racional e analítico que vai desde a identificação do problema de inteligência, até a adequada difusão dos produtos para os tomadores de decisão. Esse entendimento é empregado pelo nosso já conhecido oficial militar na seguinte frase: "Somente com inteligência poderemos descobrir o potencial logístico do inimigo".

Se considerarmos que Kent baseou sua teoria em suas vivências profissionais, existe até uma certa lógica nessa conceituação trina, uma vez que na informalidade das comunicações entre as pessoas que trabalham na área realmente é comum o emprego do termo nesses diferentes sentidos. Portanto, os leigos ou até mesmo as pessoas que estão se iniciando no meio devem atentar para essas peculiaridades semânticas da palavra "inteligência".

O próprio Kent admite que essa natureza polissêmica do termo advém do linguajar utilizado pelos profissionais de inteligência, ou seja, nada mais é que um jargão ${ }^{3}$ :

3 O Dicionário Michaelis define jargão como: “4 fraseologia peculiar a qualquer classe, profissão etc. 5 Calão, gíria”. 
Reflexões sobre o Conceito de Inteligência

Na linguagem do ofício, a palavra informação não é apenas utilizada para designar os tipos de conhecimentos que discutimos e o tipo de organização que a produz, é usada como sinônimo de atividade que a organização desempenha. (KENT, 1967, p. 147, grifo nosso).

\section{ANÁlise CRítica}

Segundo a visão do autor deste trabalho, não existe pertinência em se transferir essa característica polissêmica do termo para o conceito geral do que é inteligência, uma vez que a ambiguidade inerente à definição trina, ao invés de facilitar o entendimento do conceito, dificulta. A análise abaixo de frases usualmente pronunciadas dá uma noção do problema:

- "A inteligência diz que as organizações criminosas estão se reestruturando" (A frase não permite concluir se o produto de inteligência é quem diz, ou se o órgão de inteligência é quem diz);

- "Graças à inteligência, foi possível neutralizar a ação do inimigo" (Este exemplo é ainda mais emblemático. Nele é possível interpretar o termo "inteligência" de acordo com seus três significados; graças ao produto de inteligência elaborado, graças ao órgão de inteligência, ou graças à atividade de inteligência, foi possível neutralizar a ação do inimigo?);

- "A inteligência é um grande aliado do tomador de decisão" (Mais um exemplo em que a palavra "inteligência" pode ser entendida segundo seus três diferentes usos; o produto de inteligência é um grande aliado, o órgão de inteligência é um grande aliado, ou atividade de inteligência é uma grande aliada?).

Há de se mencionar também que, de maneira geral, tudo aquilo que permite várias interpretações gera polêmica, isso porque abre espaço para o uso exacerbado da subjetividade. Além disso, faz parte da natureza humana se distanciar, se manter alheio, não se interessar, ou então rechaçar e negar coisas que sejam de difícil compreensão ou que não ficaram bem compreendidas.

Nesse sentido, acredita-se que a falta de compreensão do que realmente caracteriza e compóe a atividade de inteligência tem sido a gran- 
de responsável por inúmeros equívocos cometidos durante o seu processo de disseminação, evolução e legitimação ocorrido a partir da segunda metade do século XX.

Quando a atividade de inteligência passou a ser empregada em áreas de interesse diversas das tradicionais (defesa nacional e segurança da sociedade), a falta de compreensão a respeito de sua essência acabou fazendo com que teóricos criassem conceitos tautológicos, sobrepusessem conceitos desnecessariamente e até mesmo cometessem erros conceituais.

No campo da profissionalização e institucionalização da atividade, esses dilemas levaram ao estabelecimento de códigos de ética e doutrinas inadequados, criação de sistemas e estruturas organizacionais ineficientes e ineficazes, além de legislações pouco alinhadas com as necessidades e possibilidades operacionais da área.

Por fim, resta dizer que, apesar de não ser o único fator a ser considerado, a dificuldade de se entender o que é inteligência contribui para a mistificação e a marginalização da atividade perante a sociedade de uma maneira geral. Definições vagas, pouco conclusivas, e explicações genéricas que são apresentadas aos leigos, associadas à aura de segredo que envolve a atividade, certamente geram desconfiança e receio nos diversos setores sociais.

Além dos aspectos já expostos, outro risco da adoção de uma definição polissêmica é o perigo da vulgarização e banalização do conceito, na medida em que se abre a perspectiva de futuramente outros autores atribuírem novos significados ao termo. Neste caso, ao descrever uma variedade grande de coisas, o conceito se esvazia, perde sua força, importância e passa a representar efetivamente nada.

Algumas ocorrências nesse sentido já podem ser constatadas atualmente. É o caso de empresas que coletam e analisam dados provenientes de fontes abertas que, por questóes mercadológicas ou por puro desconhecimento do conceito, dizem realizar inteligência. Ora, se aceitarmos a possibilidade de uma fração do processo poder significar o todo, elas teriam razão.

Adequada ou não, o fato é que a definição trina de Sherman Kent tornou-se referência dentro da comunidade de inteligência internacional, influenciando até hoje importantes autores e fazendo parte de inúmeras doutrinas mundo afora. 
Exemplo disso é o conceito de inteligência utilizado pelo Grupo de Assessoramento do Setor de Segurança do Reino Unido ${ }^{4}$ :

Inteligência é um processo pelo qual dados são refinados em uma forma útil para os tomadores de decisão. É também uma estrutura de organizações que coleta e processa informação. (HANNAH; O'BRIEN; RATHMELL, 2005, p. iv, tradução livre, grifo nosso).

No livro Intelligence 2000: Revising the Basic Elements, publicado pela International Association of Law Enforcement Intelligence Analysts (IALELA), cuja abordagem do tema se dá basicamente em relação à inteligência criminal, também não fica claro qual das visões é adotada. $\mathrm{Na}$ definição de inteligência criminal mencionada logo na primeira página do livro, lê-se:
Inteligência criminal éum processo (discutido em detalhes na Seção II) que envolve a coleta, avaliação, coleção, análise, disseminação e reavaliação de informação de criminosos e organizaçôes suspeitas. (HARRIS, 1976, apUd PETERSON, MOREHOUSE, WRI- GHT, 2002, p. 1, tradução livre, grifo nosso).

Mais à frente, entretanto, admitindo a polissemia do termo, Morehouse afirma que a dimensão produto é a mais aceita.

\begin{abstract}
Inteligência criminal evoca uma variedade de significados [...]. Inteligência pode ser considerada a informação coletada ou uma função específica. Entretanto, é geralmente admitido que inteligência consiste em pedaços de informação bruta que, quando coletada, avaliada, colecionada e analisada, levam a julgamentos significativos e úteis que são tanto precisos quanto oportunos. (PETERSON; MOREHOUSE; WRIGHT, 2002, p. 7, tradução livre, grifo nosso).
\end{abstract}

Cepik, por sua vez, também contempla essa multiplicidade de sentidos. Como dito anteriormente, a revisão literária feita por ele sintetiza dois usos do termo inteligência fora do âmbito das ciências cognitivas. A acepção ampla refere-se claramente ao produto final da atividade, já que diz que "inteligência é toda informação coletada, organizada e analisada para atender as demandas de um tomador de decisão qualquer" (2001, p. 2). A restrita, por outro lado, faz alusão à dimensão processo, pois enfatiza a coleta de dados negados 5 .

Ao associar essas duas dimensões, ele volta a explicitar a questão do processo:

4 United Kingdom's Security Sector Advisory Team.

5 Essa definição restrita já fora transcrita na página 13 deste artigo. 
A combinação dessas duas faces ou dimensões fundamentais do conceito de inteligência traduz-se numa organização caracteristica do processo de trabalho ai envolvido. (CEPIK, 2001, p. 31).

Apesar de não se negar que, no jargão profissional, a palavra "inteligência" realmente apresenta três sentidos distintos, baseado no exposto, acredita-se ser mais pertinente considerar, para fins acadêmicos, o conceito de inteligência apenas como sendo uma atividade, um processo, um método sistemático e contínuo assemelhado ao método científico.

Tal conclusão se deve ao fato de que o significado de um termo deve priorizar necessariamente a sua essência, os seus elementos distintivos, as suas características inequívocas.

Nesse sentido, ao se considerar que o cerne da inteligência é prover produtos informacionais que procuram explicar, estimar e predizer eventos, a dimensão atividade contempla, portanto, a maneira com que essa produção se dá. O teor e a natureza das ações, assim como a forma com que elas são concatenadas. Os métodos, metodologias e técnicas empregadas.

Já a dimensão organização designa tão somente o arranjo institucional através do qual essa atividade se dispóe no intuito de cumprir seus objetivos. Assim, definir um conceito considerando apenas os modelos organizacionais que permitem que a atividade aconteça, desconsiderando-se os processos produtivos que são empregados, não parece sensato.

Mais restritivo ainda seria considerar inteligência exclusivamente como sendo um mero produto informacional. O conhecimento é tão somente uma peça analítica resultante dos esforços envolvidos na atividade, a finalização do processo, sua última etapa. Dessa forma, equiparar o conceito de inteligência ao de conhecimento, seria o mesmo que entender o termo investigação criminal como sendo sinônimo do conceito de inquérito policial.

Considerando-se, então, a pertinência de se restringir o significado acadêmico do termo inteligência a sua dimensão atividade, sugere-se que a dimensão produto, ao menos conceitualmente, deva ser tratada como "conhecimento" ou mesmo "produto de inteligência". Da mesma forma, ao se referir à dimensão estrutura, seria mais adequado que a literatura da área utilizasse as palavras "serviços de inteligência", "órgão de inteligência" e assemelhados. 


\section{Conclusão}

Procurou-se, neste artigo, por meio de uma análise das principais definições encontradas na literatura da área de inteligência, demonstrar o quanto a inexistência de uma conceituação clara e adequada dificulta o desenvolvimento da atividade.

Nesse sentido, a falta de compreensão sobre o tema é responsável pelo repúdio que se verifica em boa parte dos leigos e faz com que os profissionais da área, bem como os legisladores, equivoquem-se ao desenvolverem códigos de ética, doutrinas, estruturas organizacionais e legislações específicas.

Por outro lado, árduo se torna o trabalho de se estabelecer um conceito universalizante, uma vez que as discussões teóricas a respeito dos elementos essenciais que caracterizam essa atividade não estão pacificadas.

Ao centrar a sua apreciação na definição trina de Sherman Kent, o trabalho conclui pela necessidade de se restringir, ao menos academicamente, o significado do conceito de inteligência a sua dimensão atividade. Preterindo, assim, as dimensões produto e organização também presentes na obra do pesquisador americano.

Henrigue Figueiredo Machado de Oliveira Agente de Polícia Federal lotado na SR/DPF/MG. Graduado
em Administração pela Universidade Federal de Minas Ge-
Rais. Especialista em Inteligência de Estado e InteligênCia de
Segurança Pública pela Escola Superior do Ministério Públi-
Co de Minas Gerais. Ex-professor da Cadeira de InteligênCia
Financeira desse mesmo curso de especialização.

E-MAIL: HENRIQUE.HFMO@DPF.GOV.BR

\section{ABSTRACT}

\section{Reflections on the Concept of Intelligence}

This article presents a reflection on the concept of intelligence by means of revision of literature produced by reference authors in the area, notably the American researcher Sherman Kent. By demonstrating the inexistence of a definition encompassing the diverse elements permeating this activity in a satisfactory way, as well as the multiplicity of meanings of the term, this paper seeks to point out the negative aspects emerging from this conceptual gap.

KEYWORDS: Intelligence. Concept of Intelligence. Sherman Kent. Trine Definition. 


\section{REFERÊNCIAS}

BRASIL. Ministério da Justiça. Secretaria Nacional de Segurança Pública. Doutrina Nacional de Inteligência de Segurança Pública (DNISP). Brasília, 2007.

CEPIK, Marco A. C. Serviços de Inteligência: agilidade e transparência como dilema de institucionalização. 415f. Tese (Doutorado em Ciências Políticas) - Instituto Universitário de Pesquisa do Rio de Janeiro, Rio de Janeiro, 2001.

GONÇALVES, Joanisval Brito. A atividade de inteligência e legislação correlata. Niterói: Impetus, 2009.

FEITOZA, Denilson. Operações de inteligência, ações de busca e técnicas operacionais como provas. In: FEITOZA, Denilson. Direito processual penal: teoria, crítica e práxis. 8. ed. Rev., ampl. e atual. Niterói: Impetus, 2011. p. 1028-1053. No prelo.

HANNAH, Greg; O'BRIEN, Kevin; RATHMELL, Andrew. Intelligence and Security Legislation for Security Sector Reform. Cambridge: RAND Europe (UK), 2005. Em pdf.

HARRIS, Don R. Basic Elements of Intelligence: Revised. Washington, DC: Law Enforcement Assistance Administration, 1976. p. 1-8.

JARGÃO. In: DICIONÁRIO Michaelis. Disponível em: <http:// michaelis.uol.com.br/moderno/portugues/index.php >. Acesso em: 20 jul. 2002.

KENT, Sherman. Informações estratégicas. Rio de Janeiro: Biblioteca do Exército, 1967.

PETERSON, Marilyn B.; MOREHOUSE, Bob; WRIGHT, Richard; Intelligence 2000: Revising the Basic Elements. Lawrenceville, NJ: Law Enforcement Intelligence Unit/LEIU and International Association of Law Enforcement Intelligence Analysts/IALEIA, 2002. $245 \mathrm{p}$. 